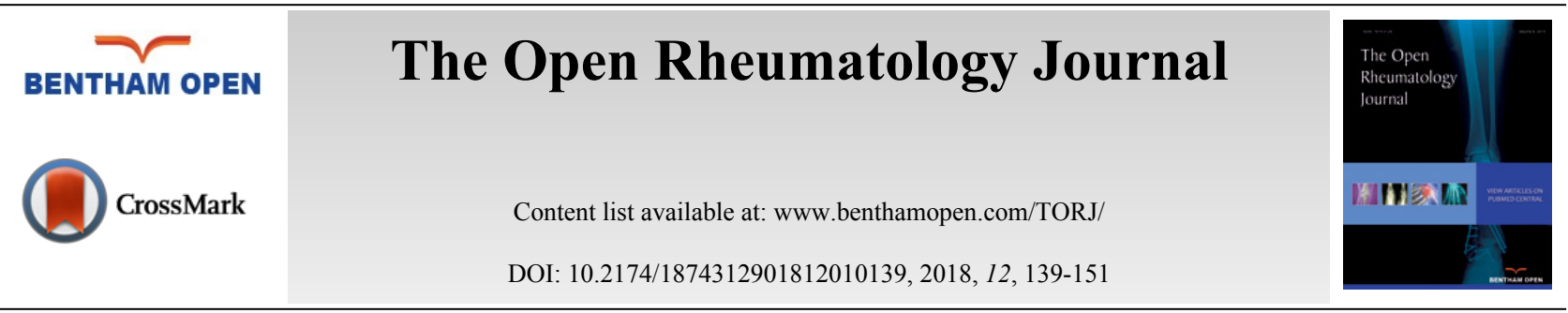

RESEARCH ARTICLE

\title{
Plasma Saturated and Monounsaturated Fatty Acids in Behçet's Disease
}

\author{
Meriam Messedi ${ }^{1}$, Manel Naifar ${ }^{2}$, Sahar Grayaa ${ }^{1}$, Faten Frikha, ${ }^{3, *}$, Mariem Messoued ${ }^{1}$, Mohamed \\ Marouene Sethom ${ }^{4}$, Moncef Feki ${ }^{4}$, Naziha Kaabach ${ }^{4}$, Zouheir Bahloul ${ }^{3}$, Kamel Jamoussi ${ }^{1}$ and Fatma \\ Ayedi $^{1,2}$ \\ ${ }^{1}$ Unit of Research Molecular Bases of Human Diseases, 12ES17, Faculty of Medicine of Sfax, University of Sfax, 3029 \\ Sfax, Sfax, Tunisia \\ ${ }^{2}$ Biochemistry laboratory, Habib Bourguiba University Hospital, 3029 Sfax, Sfax, Tunisia \\ ${ }^{3}$ Internal Medicine Department, Hedi Chaker Hospital, 3029 Sfax, Sfax, Tunisia \\ ${ }^{4}$ Faculty of Medicine of Tunis, Biochemistry laboratory, La Rabta Hospital and UR05/08-08, Tunis 1007, Tunisia
}

Received: April 23, 2018

Revised: June 9, 2018

Accepted: July 5, 2018

\section{Abstract: \\ Background:}

Fatty Acid (FA) composition of serum has been associated with many markers of inflammation. In this study, we tried to examine plasma Saturated Fatty Acid (SFA) and Monounsaturated Fatty Acid (MUFA) composition in Behçet's Disease (BD) patients. The associations between the circulating FA levels and some markers of inflammation have also been investigated.

\section{Methods:}

This study is a cross-sectional one. In fact, a total of 101 BD patients and healthy controls group of 99 subjects are enrolled. Gas Chromatograph equipped with a Capillary Split/Splitless Injector and flame ionization detector was used to analyze the plasma SFA and MUFA compositions. The high sensitivity C-Reactive Protein (hsCRP) and fibrinogen levels were measured using standard techniques.

\section{Results:}

BD patients had significantly higher proportions of Mystiric Acid (MA), Palmitic Acid (PAM), Palmitoleic Acid (POA) and Stearoyl-CoA Desaturase (SCD)-16, compared to controls.

The results revealed that patients with severe involvements had high levels of POA and total MUFA associated with higher SCD-16 activity compared to those with minor ones. The receiver operator characteristic curve analysis revealed that POA could well discriminate BD patients with severe clinical manifestations. In the bivariate analysis, hsCRP was found to be positively correlated with total SAFA and POA elongase activity index but negatively correlated with SCD-18 activity index. The STA, POA, elongase and SCD-16 activity index are correlated with fibrinogen. On the other hand, the multivariate analysis showed that POA remained associated with higher levels of hsCRP.

\section{Conclusion:}

Unfavourable plasma SFA and MUFA profile were reported in BD patients. POA, which is associated with higher plasma hsCRP level, may play a role in the pathogenesis of BD.

\footnotetext{
* Address for correspondence to this author at the Internal Medicine Department, Hedi Chaker Hospital, 3029 Sfax, Sfax, Tunisia; Tel: +00 216 98657098; E-mail: fetenfrikha@yahoo.fr
} 
Keywords: Behçet's disease, Plasma saturated fatty acids, Plasma monounsaturated fatty acids,stearoyl-CoA desaturase, Inflammation, $\mathrm{C}$ reactive proteine.

\section{INTRODUCTION}

Behcet's Disease (BD) is a relapsing chronic, multi-systemic inflammatory disorder which is classified as vasculitis [1] which is mainly characterized by oro-genital ulcers and cutaneous manifestations. Ocular inflammation, articular manifestations, vascular and neurological involvements may also occur in patients with BD [1]. The pathophysiology of this disease remains unknown and many hypotheses are intended to elucidate its etiology. Recent data suggest that BD is thought to link genetic, immuno-metabolic, inflammation and infection factors [1,2]. In fact, BD is characterized by markedly high levels of inflammatory markers including C-Reactive Protein (CRP), TNF- $\alpha$ and IL-6 among others [3 $5]$ and of activated inflammatory cells at the site of tissue damage and in the systemic circulation $[1,6]$.

Actually, several studies support the idea that a variety of dietary factors, which can modulate inflammation, are associated with specific biomarkers of inflammation, which promote the deregulation of specific immune cell subpopulations [7]. Among the many fat species, Fatty Acids (FA) seem to be the smallest but play an essential role in many cell functions. In this context, numerous studies have reported that dietary and/or blood FA compositions are associated with systemic inflammation, oxidative stress and impaired endothelial function [7, 8]. FA are energy sources and major components of cell membrane that can influence human health and well-being as well as disease risk. Moreover, they are involved in the regulation of membrane function and structure; intracellular signaling pathways, gene expression and the bioactive lipid mediators production [7]. In fact, some effects of FA on inflammatory process seem to be mediated by, or at least are associated with, modifications in fatty acid composition of plasma and cell membranes. FA belong to a chemically heterogeneous group and are classified according to their degree of desaturation, i.e., Saturated FA (SFA), Monounsaturated FA (MUFA), Polyunsaturated FA (PUFA); However, the issue of causality and the degree to which each FA might contribute and serve to promote inflammation remain fully unsolved. The pro or anti-inflammatory effects of FA depend on their chemical structure (chain long, the number and the position of double bounds). On the other hand, several observational studies have reported that $n-6$ PUFA tend to have a pro-inflammatory role, as they are the precursors of active pro-inflammatory molecules such as prostaglandins or leukotrienes [9], whereas, n-3 PUFA have been found to diminish systemic inflammation [10]. These FA can generate resolving lipids which enhance resolution mechanisms in inflammation [9]. As for MUFAs, they are widely believed to be beneficial to health, by favorably altering serum lipids and inflammation [11, 12]. However, data from cell culture have suggested that MUFA have deleterious effects on the inflammatory pathways [13, 14]. Regarding the SFA, most of the clinical trials, cohort and cell culture studies corroborate of their pro-inflammatory effects [15 - 17]. Furthermore, it has been demonstrated that SFA are associated with a high risk of many chronic inflammatory diseases such as diabetes [18], metabolic syndrome [19] and atherosclerosis [20]. Indeed, the collected data showed that plasma lipid SFA level is positively correlated the plasma levels of the CRP, fibrinogen and pro-inflammatory cytokines [21, 22]. In fact, SFA seem to stimulate inflammatory responses through immune cell effector activation and recruitment $[23,24]$.

Considering that inflammatory process and immune cells; which play a pivotal role in the physiopathology of BD; are sensitive to diet tone changes, we intended to examine plasma saturated and monounsaturated FA compositions in Tunisian BD patients. The associations between individual FA and some markers of inflammation were also performed. As such, investigations of these patients would generate new information regarding the relationships between individual FA and inflammation prior to the onset of this chronic inflammatory condition.

\section{PATIENTS AND METHODS}

\subsection{Population Study}

Tunisian BD patients, who fulfilled the criteria of the International Study Group Criteria of BD, were enrolled [25]. Samples from gender, age and Body Mass Index (BMI)-matched group of healthy controls were recruited. Clinical data about the onset of the disease, medication history, and clinical manifestations were ascertained. The clinical evaluation included information about smoking history, alcohol consumption, familial history of premature cardiovascular disease, diabetes mellitus, hypertension, and any use of medication. The BD's current activity form was determined for each patient at the time of the blood withdrawal. The BD Activity Index (BDAI) was calculated as previously reported [26]. Severe BD was defined based on clinical manifestation. The patients eligible for this group were whose had serious vital organ involvement including ocular damages, neurological lesions, vascular and gastrointestinal involvements [27, 28]. This research study has been approved by the local ethics committee and all the participants provided informed 
written consent before being enrolled in this study.

\subsection{Analytical Methods}

\subsubsection{Food Intake Assessment}

Detailed food consumption was assessed using a validated semi quantitative food frequency questionnaire adapted to the Tunisian context [29]. These data were collected through a face-to-face interview with all the participants. The Tunisian food composition database has been used to convert dietary intake data into nutrient values [30]. Then, all the calculations were performed using Bilnut software version 2.01 (S.C.D.A. Nutrisoft, Cerelles, France). The dietician registered all the meals and beverages consumed in one week for a period of one month. For the estimation of the size of individual portions, a picture booklet and household measurement units were provided to each participant. In order to determine the frequency consumption of the different food intake, participants were asked about the proportion of each item consumed per day.

\subsubsection{Blood Processing and Fatty Acid Analysis}

After an overnight fasting, whole blood specimens were collected into sodium citrate, heparin and EDTA tubes. Plasma from heparin-containing tubes was immediately used for glycaemia, lipid and high-sensitivity C-Reactive Protein (hsCRP) analyses. Glycaemia was measured using the glucose oxidase method [31]. Serum levels of total cholesterol, triglycerides and high-density lipoprotein cholesterol were measured by standard enzymatic methods. Analyses were carried out on ARCHITECT c8000 analyzer (Abott Diagnostics, Abbott Park Rd, US) using corresponding reagent kits. The low-density lipoprotein cholesterol was calculated using the formula of Friedewald [32]. Apolipoprotein A-I andapolipoprotein B 100 levels were measured by turbidmetric immunoassay using COBAS INTEGRA 400 analyzer (Roche Diagnostics Basel, Switzerland). Plasma hsCRP concentrations were measured with a particle-enhanced immune-turbidimetric assay (Roche Tina-Quant CRP, Roche Diagnostics, Basel, Switzerland). Samples of citrate plasma were analyzed within $2 \mathrm{~h}$ of venipuncture by an automatic coagulometer (Multifibren, BCS, Siemens Healthcare Diagnostics) for fibrinogen measurements.

\subsubsection{Analysis of Plasma FA Using Gas Chromatography}

For FA, plasma from EDTA-tubes was used. In fact, plasma samples were separated within 1 hour by centrifugation at $1000 \times \mathrm{g}$ for $10 \mathrm{~min}$, followed by the addition of an antioxidant butylated hydroxyl toluene and stored at $-80^{\circ} \mathrm{C}$. FA were analyzed using a gas chromatography model 6890N (Agilent Technologies), equipped with a split/splitless capillary Intel system and a flame ionization detector. A polyethylene glycol fused silica capillary column (Innowax, 30 m $90.25 \mathrm{~mm} 90.25 \mathrm{~lm}$ film thickness) purchased from Agilent (Wilmington, Delaware, USA) was used. The injector and detector temperatures were 230 and $280^{\circ} \mathrm{C}$, respectively. The flow-rate of nitrogen as the carrier gas was set to 1.5 $\mathrm{ml} / \mathrm{min}$ in a constant flow mode. The oven temperature was held at $150^{\circ} \mathrm{C}$ for $1 \mathrm{~min}$, then programmed at a rate of $15^{\circ} \mathrm{C} / \mathrm{min}$ to increase up to $210^{\circ} \mathrm{C}$ and kept constant during $5 \mathrm{~min}$ then subsequently programmed at $250^{\circ} \mathrm{C}$ with a rate of $4^{\circ} \mathrm{C} / \mathrm{min}[33]$.

Peak areas were quantified using chromatography software (Agilent Technologies Chem Station FamilyR data analysis). The fatty acid methyl esters, which were first identified by comparing their retention times to those of known standards and results, were expressed as relative percentages of each FA.

As estimated enzyme activities from serum fatty acid ratios has been shown to approximate liver enzyme activities [34], elongase and desaturase indices were estimated according to the following:elongase $=\mathrm{C} 18: 0 / \mathrm{C} 16: 0 ;$ Stearoyl-CoA Desaturase-18 $($ SCD-18) $=\mathrm{C} 18: 1 \mathrm{n}-9 / \mathrm{C} 18: 0$, Stearoyl-CoA Desaturase-16 $(\mathrm{SCD} 16)=\mathrm{C} 16: 1 \mathrm{n}-7 / \mathrm{C} 16: 0$.

In the current study, the authors examined the plasma SFA and MUFA levels using relative percentage ( $\%$ of total FA) and absolute concentration $(\mu \mathrm{g} / \mathrm{ml})$ methods. The long-term imprecision $(\mathrm{CV})$ was less than $10 \%$ for each fatty acid [33].

\subsection{Statistical Analysis}

Statistical analyses were performed using the SPSS software package (version 20.0 for windows; SPSS Inc. Chicago, IL, USA). Continuous variables were given as the mean (standard deviation) and analyzed by Student $t$-test. Since our cohort showed a non-Gaussian distribution, some non-parametric statistical methods (Mann-Whitney $U$ - and chi-squared tests) were used to analyze the data and results were expressed as median (25th-75th percentile). Receiver 
Operating Characteristic Curves (ROC) was performed to identify a predictive markers for diagnostic of severe form of BD. Area Under the Curve (AUC), cutoff values together with degree of specificity and sensitivity were calculated. Pearson's and Spearman's correlation tests were used to evaluate the associations between continuous variables with Gaussian distribution and non-Gaussian distribution, respectively. The regression models adjusted for age, gender, BMI, smoking and lipid parameter levels were used to evaluate the associations between plasma SFA and MUFA and the markers of inflammation. The odds ratios and 95\% Confidence Intervals (CIs) for FA were calculated by binary logistic regression models. The reported $p$-values were based on two-tailed calculations and values less than 0.05 were considered as a statistically significant level.

\section{RESULTS}

\subsection{Studied Population Characteristics}

A cohort of 142 BD patients and 139 healthy controls were enrolled. All the subjects with a history of early cardiovascular disease, hypertension, diabetes, dyslipidaemia, overweight, smoking, drinking and any other chronic inflammatory condition as well as any subjects treated with Statins, asprin or corticoids; at least one month before the blood withdrawal, have been excluded. After a selection operation, the studied population consists of 101 BD patients (72 men and 29 women) and 99 healthy controls ( 70 men and 29 women). The clinical features of BD patients were summarized in Table 1. Anthropometric, demographic and clinical variability including sex ratio, age, systolic and diastolic blood pressures, BMI measurement were similar in both groups. The laboratory values did not differ between the $\mathrm{BD}$ patients and the controls except for plasma high-density lipoprotein cholesterol level $(1.23 \mathrm{mmol} / \mathrm{L}$ vs $1.11 \mathrm{mmol} / \mathrm{L}, p=0.02)$ and $\mathrm{hsCRP}(2.6 \mathrm{mg} / \mathrm{mL}$ vs $1.37 \mathrm{mg} / \mathrm{mL}, p=0.001)$ (Data not shown).

Table 1. Clinical features of BD patients.

\begin{tabular}{|c|c|}
\hline Characteristics & $\mathbf{n}=\mathbf{1 0 1}$ \\
\hline Disease duration, months & $124(2-326)$ \\
\hline Genital ulcer, $\mathrm{n}(\%)$ & $80(80 \%)$ \\
\hline Papulopustular lesions, $\mathrm{n}(\%)$ & $82(81 \%)$ \\
\hline Erythema nodosum-like lesions, $\mathrm{n}(\%)$ & $10(9 \%)$ \\
\hline Positive pathergy test, $\mathrm{n}(\%)$ & $48(47 \%)$ \\
\hline Arthritis, $\mathrm{n}(\%)$ & $38(37 \%)$ \\
\hline Ocular involvement, $\mathrm{n}(\%)$ & $39(38 \%)$ \\
\hline Posterior uveitis, $\mathrm{n}(\%)$ & $20(19 \%)$ \\
\hline Panuveitis, $\mathrm{n}$ (\%) & $16(15 \%)$ \\
\hline Retinal vasculitis, $\mathrm{n}(\%)$ & $24(23 \%)$ \\
\hline Deep vein thrombosis, $\mathrm{n}(\%)$ & $26(25 \%)$ \\
\hline Neurological involvement, $\mathrm{n}(\%)$ & $23(22 \%)$ \\
\hline
\end{tabular}

$\%$ : percentage, n: number.

\subsection{Fatty Acid Profile}

Actually, no significant difference was observed between the two studied groups regarding the dietary intake, energy intake, macro- and micro- nutriments, and dietary FA (Table 2). On the other hand, plasma fatty acids composition was significantly different between the BD patients and the healthy controls. In fact, BD patients had significantly higher proportions of Mystiric Acid (MA), Palmitic Acid (PAM) and total SFA compared to the controls group. Moreover, no difference was observed regarding Stearic Acid (STA) or Oleic Acid (OLA). The expected SCD-16 activity was markedly higher in patients compared to the controls but no significant difference was detected for the other studied enzymatic activity indices (Table 3).MUFA and Palmotoleic Acid (POA) were significantly more abundant in BD patients (Table 2). BD patients with severe form had also higher concentrations of POA and total MUFA associated with increased SCD-16 activity (Table 4). A Receiver Operator Characteristic (ROC) analysis, corresponding to POA concentrations in plasma as biomarker of severe form, showed an area under curve of 0.85 (95\% confidence interval: $0.72-0.99, p$-value $=10^{-3}$ ) and a predictive threshold value of $108 \mu \mathrm{g} / \mathrm{mL}$. The found sensitivity and specificity of POA found were $92 \%$ and $65 \%$, respectively (Fig. 1). 
Table 2. Dietary intake comparison in the studied populations.

\begin{tabular}{|c|c|c|c|}
\hline Parameters & Healthy Controls $(n=99)$ & BD Patients $(n=101)$ & $P$-Value \\
\hline $\begin{array}{c}\text { Energy } \\
\text { Total energy (Kcal) }\end{array}$ & $3265(2375.75-4300.50)$ & $3297(2452.5-4300)$ & 0.75 \\
\hline \multicolumn{4}{|c|}{ Macronutrients } \\
\hline Protein (g/day) & $98.8(10.2)$ & $91.2(9.1)$ & 0.33 \\
\hline Carbohydrates (g/day) & $392.1(276.9-432.7)$ & $396.9(301.3-444.1)$ & 0.18 \\
\hline Fiber (g/day) & $27.26(19.45-38.9)$ & $24.3(15.87-39.2)$ & 0.26 \\
\hline Total fat (g/day) & $88(71.8-102.3)$ & $94(77.56-120.3)$ & 0.36 \\
\hline Total SFA (\%) & $11.45(9.77-13.05)$ & $10.38(8.96-12.26)$ & 0.21 \\
\hline Total MUFA (\%) & $14.81(11.49-17.74)$ & $14(9.71-19.59)$ & 0.19 \\
\hline Total PUFA (\%) & $11.77(4.93-18.23)$ & $12.44(5.01-20.02)$ & 0.33 \\
\hline \multicolumn{4}{|c|}{ Micronutrients (/day) } \\
\hline Calcium (mg) & $542(301.5-789)$ & $578.5(437.5-826)$ & 0.54 \\
\hline Iron $(\mathrm{mg})$ & $14.18(11.28-17.05)$ & $13.42(10.12-17.1)$ & 0.31 \\
\hline Vitamin B12 $(\mu \mathrm{g})$ & $5.4(4.5-6.7)$ & $4.5(3.9-6.4)$ & 0.57 \\
\hline Vitamin C (mg) & $98(59.5-171.5)$ & $89(45-150)$ & 0.5 \\
\hline Vitamin E (mg) & $13.7(8.44-30.5)$ & $14.23(10.56-31.20)$ & 0.59 \\
\hline Folates $(\mu \mathrm{g})$ & $223.4(191.25-271.15)$ & $225.8(205.25-274.72)$ & 0.8 \\
\hline Sodium (mg) & $2692(2463.25-3206.75)$ & $2536(2315-2939.5)$ & 0.21 \\
\hline Potassium (mg) & $2963(2624-3683.25)$ & $2827(1588-2306.5)$ & 0.42 \\
\hline Phosphore (mg) & $1210.5(1026.25-1475)$ & $1116(957.5-1389.75)$ & 0.49 \\
\hline Magnesium (mg) & $296(204.25-347)$ & $307(223-448)$ & 0.4 \\
\hline Zinc (mg) & $9.29(8.48-10.96)$ & $9.52(8.88-11.59)$ & 0.31 \\
\hline
\end{tabular}

SFA: Saturated Fatty Acids; MUFA: Monounsaturated Fatty Acids; PUFA: Polyunsaturated Fatty Acids; Kcal: Kilocalories; g:gram; \%: percentage; mg: milligrams; $\mu \mathrm{g}$ : micrograms; /: per.

Table 3. Plasma saturated and monounsaturated fatty acids profile and estimated enzymatic activities indices in BD patients and controls.

\begin{tabular}{|c|c|c|c|c|}
\hline \multirow[t]{2}{*}{ - } & \multicolumn{2}{|c|}{ Controls $(\mathrm{n}=99)$} & \multicolumn{2}{|c|}{ BD Patients $(n=101)$} \\
\hline & $\%$ & $\mu \mathrm{g} / \mathrm{ml}$ & $\%$ & $\mu \mathrm{g} / \mathrm{ml}$ \\
\hline MA (C14:0) & $0.63(0.50-0.84)$ & $26.28(17.87-40.28)$ & $0.75(0.55-0.98)^{*}$ & $27.96(19.46-42.49)^{*}$ \\
\hline PAM (C16:0) & $21.87(20.25-23.26)$ & 856.17 (622.15-1082.05) & $22.31(20.87-24.88)^{*}$ & 881.54 (664.0-106.69)* \\
\hline STA (C18:0) & $6.09(5.26-6.70)$ & $237.45(182.05-304.20)$ & $6.04(5.31-7.59)$ & $233.11(174.75-311.84)$ \\
\hline Total SFA & $28.49(26.67-30.98)$ & $1070.70(891.52-1376.28)$ & $29.65(27.24-32.43) *$ & 1156.77 (818.69-1408.79)* \\
\hline POA (C16:1n-7) & $2.94(2.01-4.26)$ & $107.27(72.56-168.15)$ & $3.88(2.72-5.51)^{* * *}$ & $130.13(89.08-188.76) *$ \\
\hline OLA (C18:1n-9) & $21.5(19.79-23.66)$ & $639.81(465.18-892.30)$ & $20.7(18.78-23.28)$ & $584.72(429.67-827.62)$ \\
\hline Total MUFA & $24.73(22.88-27.09)$ & 707.27 (543.81-976.93) & $25.25(22.52-28.4)$ & $741.23(536.35-1064.83)$ \\
\hline Elongase & $0.28(0.24-0.31)$ & $0.28(0.25-0.31)$ & $0.27(0.23-0.32)$ & $0.27(0.23-0.32)$ \\
\hline SCD-16 & $0.13(0.09-0.19)$ & $0.12(0.09-0.178)$ & $0.17(0.12-0.24)^{* * *}$ & $0.15(0.11-0.21)^{*}$ \\
\hline SCD-18 & $3.55(2.91-4.49)$ & $2.73(2.27-3.46)$ & $3.30(2.53-4.37)$ & $2.53(1.98-3.40)$ \\
\hline
\end{tabular}

BD: Behcet Disease; MA: Mystiric. PAM: Palmitic acid; STA: Stearic acid; POA: Palmitoleic acid; OLA: Oleic acid; SFA: Saturated fatty acids; MUFA: Monounsaturated fatty acids; SCD: Stearoyl CoA desaturase; \%: percentage; $\mu \mathrm{g}$ :microgram ; ml: milliliter; $\mu$ mol: micromole; *: $p \leq 0,05 ; * *$ : $p \leq 0,001$.

Table 4. Comparison of plasma saturated and monounsaturated fatty acids profile and estimated enzymatic activities indices between $B D$ patients with minor and with severe clinical manifestations.

\begin{tabular}{|c|c|c|c|c|}
\hline- & \multicolumn{2}{|c|}{ BD patients with minor clinical manifestations (n=57) } & BD patients with severe clinical manifestations $(\mathbf{n}=\mathbf{4 4})$ \\
\hline- & $\mathbf{\%}$ & $\boldsymbol{\mu g} / \mathbf{m l}$ & $\mathbf{\%}$ & $\boldsymbol{\mu g} / \mathbf{m l}$ \\
\hline MA (C14:0) & $0.60(0.45-0.85)$ & $26.09(15.86-32.72)$ & $0.80(0.59-0.94)$ & $29.24(21.87-45.71)$ \\
\hline PAM (C16:0) & $22.31(20.74-24.59)$ & $720.26(647.02-952.61)$ & $21.78(20.56-24.62)$ & $916.79(732.59-1092.74)$ \\
\hline STA (C18:0) & $6.11(5.32-7.62)$ & $213.28(156.72-276.56)$ & $5.92(4.86-7.27)$ & $227.77(174.78-329.20)$ \\
\hline Total SFA & $29.42(27.14-33.22)$ & $959.79(832.17-1236.87)$ & $28.23(25.98-31.76)$ & $1152.89(1011.23-1461.96)$ \\
\hline
\end{tabular}




\begin{tabular}{|c|c|c|c|c|}
\hline POA (C16:1n-7) & $3.56(2.18-5.02)$ & $101.33(76.60-144.29)$ & $5.11(3.61-6.33)^{* *}$ & $191.64(159.49-252.41) * *$ \\
\hline OLA (C18:1n-9) & $20.15(18.57-22.70)$ & $542.40(400.92-672.51)$ & $22.0(20.59-27.20)$ & $699.96(570.11-1043.40)$ \\
\hline Total MUFA & $23.81(21.34-27.13)$ & $638.50(512.01-787.02)$ & $27.69(25.45-30.62)^{*}$ & $941.61(734.08-1265.42) * *$ \\
\hline Elongase & $0.27(0.24-0.31)$ & $0.28(0.25-0.32)$ & $0.27(0.22-0.32)$ & $0.25(0.21-0.31)$ \\
\hline SCD-16 & $0.15(0.09-0.21)$ & $0.13(0.08-0.19)$ & $0.23(0.15-0.30) * *$ & $0.21(0.15-0.27)^{* *}$ \\
\hline SCD-18 & $3.17(2.56-4.28)$ & $2.48(2.05-3.28)$ & $3.81(3.11-5.06)$ & $3.43(2.61-3.88)$ \\
\hline
\end{tabular}

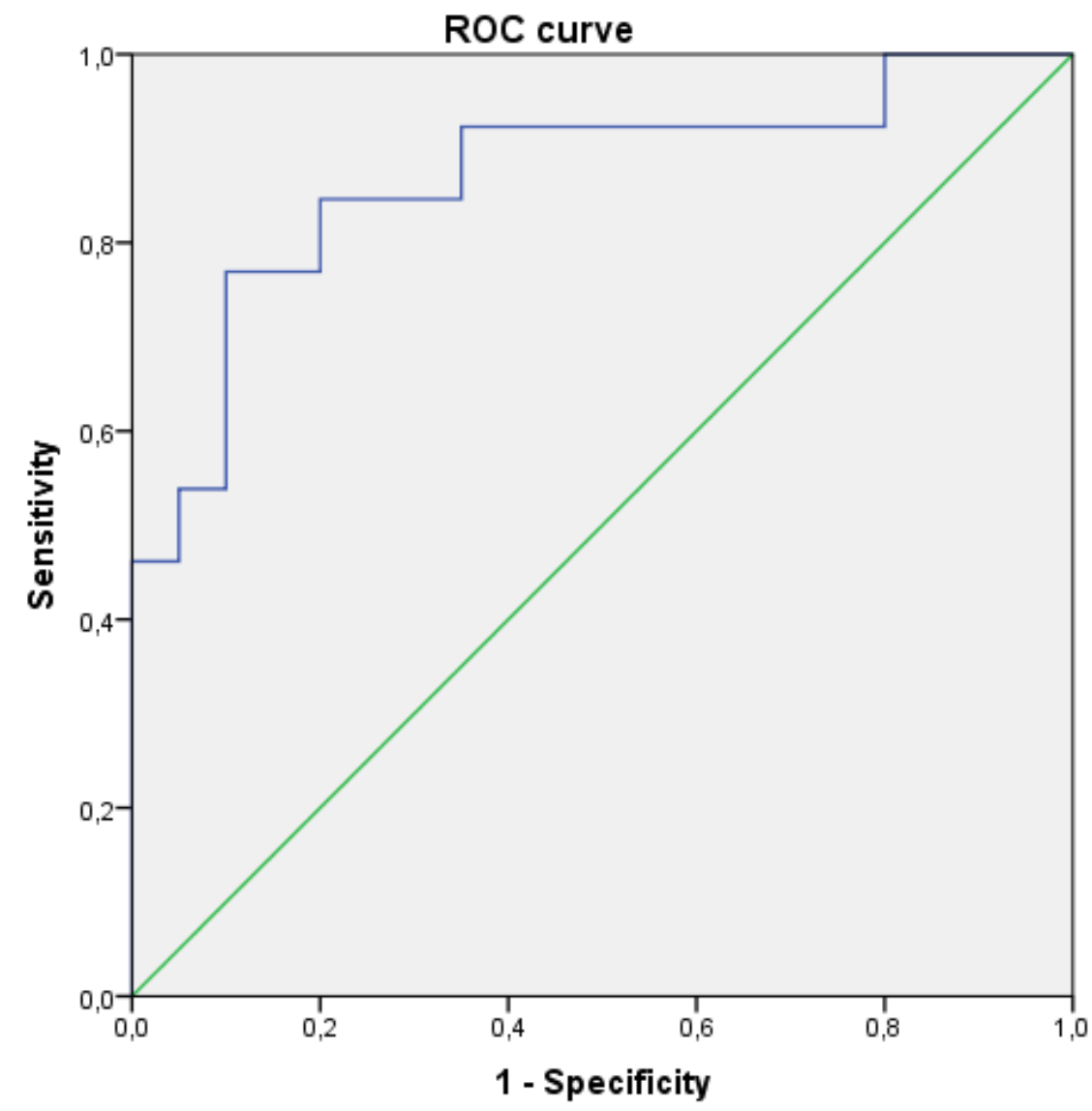

Fig. (1). Receiver Operating Characteristic (ROC) curve analysis of plasmatic palmitoleic acid to predict severe form of Behcet's Disease.

\subsection{Correlations between Plasma Fatty Acids and Inflammation Markers in BD Patients}

In BD patients group, hsCRP was positively correlated with elongase activity index (absolute value), total SAFA and POA (relative values) but negatively with SCD-18 activity (absolute value). The MA, PAM and STA were not associated with hsCRP when expressed as relative and absolute values (Table 5), while the STA; in its relative and absolute values; was only correlated with fibrinogen.

Table 5. Correlations between plasma saturated and monounsaturated fatty acid $s$ and studied inflammation markers in Behcet's disease.

\begin{tabular}{|c|c|c|c|c|}
\hline \multirow{2}{*}{ Plamsa FA } & \multicolumn{2}{|c|}{ hsCRP } & \multicolumn{2}{|c|}{ Fibrinogen } \\
\cline { 2 - 5 } & $\begin{array}{c}\text { Absolute } \\
(\boldsymbol{\mu g} / \mathbf{m l})\end{array}$ & $\begin{array}{c}\text { Relative } \\
(\mathbf{\%})\end{array}$ & $\begin{array}{c}\text { Absolute }(\boldsymbol{\mu g} / \mathbf{m l}) \\
(\mathbf{\%})\end{array}$ \\
\hline MA (C14:0) & -0.111 & -0.082 & -0.036 & -0.052 \\
\hline PAM (C16:0) & 0.062 & 0.147 & 0.181 & 0.131 \\
\hline STA (C18:0) & 0.185 & 0.09 & $\mathbf{0 . 3 0 2 * *}$ & $\mathbf{0 . 4 0 8}^{* *}$ \\
\hline Total SFA & 0.188 & $\mathbf{0 . 2 2 6} *$ & 0.110 & 0.159 \\
\hline POA (C16:1n-7) & 0.178 & $\mathbf{0 . 2 6 1 *}$ & $\mathbf{0 . 3 0 2 *}$ & $\mathbf{0 . 2 7 1}^{*}$ \\
\hline OLA (C18:1n-9) & -0.154 & -0.081 & -0.038 & -0.050 \\
\hline
\end{tabular}


(Table $\square$ ) contd.....

\begin{tabular}{|c|c|c|c|c|}
\hline \multirow[t]{2}{*}{ Plamsa FA } & \multicolumn{2}{|c|}{ hsCRP } & \multicolumn{2}{|c|}{ Fibrinogen } \\
\hline & $\begin{array}{c}\text { Absolute } \\
(\mu \mathrm{g} / \mathrm{ml})\end{array}$ & $\begin{array}{c}\text { Relative } \\
(\%)\end{array}$ & Absolute $(\mu \mathrm{g} / \mathrm{ml})$ & $\begin{array}{c}\text { Relative } \\
(\%)\end{array}$ \\
\hline Total MUFA & -0.157 & -0.065 & -0.083 & -0.025 \\
\hline Elongase & $0.276 *$ & 0.127 & $0.380 * *$ & $0.313 * *$ \\
\hline SCD-16 & 0.183 & 0.185 & $0.217 *$ & $0.254 *$ \\
\hline SCD-18 & $-0.264 *$ & -0.053 & -0.174 & $-0.248 *$ \\
\hline
\end{tabular}

On the other hand, the POA, elongase and SCD-16 activities were also correlated also with fibrinogen when expressed as absolute and relative values. However, a negative correlation was found between the relative value of SCD-18 and fibrinogen (Table 5). Moreover, the multiple linear regression adjusted for age, gender, BMI, smoking and lipid parameter levels revealed that the POA remained significantly associated with higher hsCRP (Table 6). However, no association with fibrinogen has been reported.

Table 6. Logistic regression that evaluate the association between palmitoleic acid andhsCRP.

\begin{tabular}{|c|c|c|}
\hline Independent & Model 1: $\boldsymbol{\beta}$ (95\% CI) & hsCRP \\
\hline- & $31.08[2.41-400.59]$ & $11.42[1.25-85.64]$ \\
\hline POA (C16:1n-7) & Model2: $\boldsymbol{\beta}$ (95\% CI) \\
\hline
\end{tabular}

Logistic regression (Wald) was used for multivariate analysis, adjustment co-variables are age, gender, BMI, smoking and lipid parameter levels. POA: Palmitoleic Acid, hsCRP: high-sensitivity C-Reactive Protein; ${ }^{a}$ hsCRP was modeled as categorical variable stratifying hsCRP levels into two groups according to the mean value observed (i.e., 2.6); model 1 when variables are expressed as absolute values, $p$-value $=<10^{-3}$; model 2 when variables are expressed as relative values, $p$-value $=<10^{-3} ; \mathrm{CI}$ : Confidence Interval

\section{DISCUSSION}

In the current study, we have examined circulating SFA and MUFA levels and laboratory data. It is worth noting that in our study, we have used plasma FA to assess their concentrations in the human body. Because FA acids in the blood compartments and tissues are highly correlated [35], plasma FA levels should reflect their concentrations in the tissues. It is well known that differences in diets would influence the blood and tissue composition of some fatty acids. Therefore, the dietary intake in the two studied population was assessed. Since the dietary intake was similar, our results of altered FA profile may be explained, at least in part with the metabolic disturbances of the BD patients.

BD: Behcet Disease; MA: Mystiric. PAM: Palmitic Acid; STA: Stearic Acid; POA: Palmitoleic Acid; OLA: Oleic Acid; SFA: Saturated Fatty Acids; MUFA: Monounsaturated Fatty Acids; SCD: Stearoyl CoA Desaturase; \%: percentage; $\mu \mathrm{g}$ :microgram ; ml: milliliter; $\mu$ mol: micromole; *: $p \leq 0,05 ; * *: p \leq 0,001$.

MA: mystiric. PAM: palmitic acid; STA: stearic acid; POA: palmitoleic acid; OLA: oleic acid; SFA: saturated fatty acids; MUFA: Monounsaturated fatty acids; SCD: stearoyl CoA desaturase; hsCRP: high-sensitivity C-reactive protein; $\%$ percentage; $\mu \mathrm{g}$ : micrograms; ml: milliliter; $*: p \leq 0.05 ; * * p \leq 0.001$.

Moreover, higher MA, PAM and total SFA levels were observed in BD compared to the healthy control subjects. In fact, $\mathrm{BD}$ is a systemic inflammatory disorder characterized by immunological abnormalities [36]. The immune system effectors cells, mainly neutrophils and macrophages sense nutrient imbalances. SFA are believed to substantially promote to pro-inflammatory state. Besides, the SFA could exacerbate inflammatory responses through various mechanisms. On the other hand, in vitro studies, have reported that SFA, mainly PA, activate inflammatory signaling, including the Nuclear Factor $\mathrm{\kappa B}(\mathrm{NF}-\mathrm{\kappa B})$ pathway and enhance the inflammatory cytokines synthesis in the vasculature and in leukocytes [37 - 39]. Moreover, SFA may modulate cytokines production through epigenetic modifications of their DNA promoter [40]. Additionally, SFA were shown to incapable of increasing Nitrous Oxide (NO) production and cyclooxygenase-2 (COX-2) mRNA expressions [41, 42]. High levels of SFA, which were reported in our BD patients, may enhance the pro-inflammatory condition and chronic inflammation, hallmarks of BD [43]. This seems to be in conformity with the data suggesting that SFA are associated with chronic inflammatory disease such as Crohn's disease [44] and psoriasis [45].

Our results also reported increased level of POA, a view which was supported by enhanced SCD-16 activity also observed in BD patients. Severe form of BD was associated with higher levels of POA, total MUFA and SCD-16 activity. Interestingly, a high plasma level of POA also seems to be a good predictor of severe form of BD. Furthermore, POA and SCD-16 were positively correlated with the high level of hsCRP while the proportion of POA remained strongly associated with this marker even after multivariable adjustment. 
In the human body, the dietary origin of POA is negligible because of its rapid oxidation after absorption. The tissue and blood concentrations of POA mainly reflect de novo lipogenesis mediated by SCD, a key enzyme of the biosynthesis of MUFA from SFA. The POA and SCD, have been recently gaining increasing attention. It has been shown that high levels of POA and SCD-16 activity were associated with many inflammatory conditions such as Crohn's [44] and chronic kidney [46, 47] diseases, cancers [48, 49] and diabetes [50]. The biological mechanisms through which POA or SCD-16 activity might exert their effects on inflammation are still unclear. Probably, the most interesting evidence is generated from the longitudinal study of Petersson et al. [51], in which POA as well as SCD-1 at the age of 50 are associated with CRP measured 20 years later in a cohort of 767 men. Such an association has been observed in Finnish 1373 men [52]. These results are in line with the findings of Stryjecki [53] who revealed a positive association between POA and CRP levels in females of both European and Asian descendants. Similar to our results, the reported associations in these studies remained significant after adjusting for covariates (e.g. age, BMI, gender, energy intake), arguing that POA is independently associated with an inflammatory state. It is not fully understood why SCD-16 and its product, POA, are associated with CRP. Nevertheless, the regulation of inflammatory pathways is extremely complex and occurs as a result of both cellular crosstalk and intracellular signaling pathways. Previous findings have demonstrated that POA up-regulate both the expression and synthesis of pro-inflammatory cytokines mainly Interleukin-6 (IL-6) and tumor necrosis factor- $\alpha$ (TNF- $\alpha$ ) [54, 55] via NFkB activation [56, 57]. Moreover, the experimental data revealed that pro-inflammatory cytokines (IL-1, IL-6, TNF- $\alpha$ ) synergistically acting would induce CRP gene transcription by controlling nuclear transcription factors [58, 59].

It is also possible that inflammation could be enhanced by a metabolic disorder associated with elevated POA level and SCD-1 activity. Indeed, several human observational studies showed that high POA concentrations in various tissues are linked to unfavorable metabolic outcomes. According to the Uppsala Longitudinal Studies, POA in adipose tissue and in serum was associated with an increased risk of developing metabolic syndrome after 20 years of follow-up in 706 men [47]. Furthermore, POA was correlated with several cardiometabolic risk factors, including higher BMI and blood pressure, plasma total cholesterol, triglycerides, apolipoprotein A-I, apolipoprotein Band endothelial dysfunction $[60,61]$. The existing data suggest that the products of SCD-1 (OLA and POA), are essential components for the production of triglycerides and cholesterol esters [62]. As a consequence, this might clarify the association of POA with increased triglycerides and cholesterols levels in human studies [62].

On the other hand, several studies have demonstrated the beneficial role of POA in inflammation and metabolic outcomes. For example, healthy participants who received a 30days supplementation of purified POA, showed reduction of CRP, triglyceride and of low-density lipoprotein levels and a significant increase in high-density lipoprotein concentration [63]. In another study conducted on 20 patients with ulcerative colitis, an eight week treatment of Cis-POA seems to decrease inflammation through the decrease of hsCRP level [64].

On the other hand studies conducted on animal showed favorable effects of POA. The mice macrophages treated with POA showed a decreased of NF- $\mathrm{BB}$ phosphorylation and reduced expressions of pro-inflammatory cytokines [65 67]. It has been also shown that POA contribute to decrease the levels of pro-inflammatory cytokines (IL-1 $\beta$, IL-6 and TNF- $\alpha)[55,68]$ as well as the expression of TLR4 [68] in obese mice liver.

The contradicting findings of the POA effect on the inflammatory process and metabolic disturbance from available data deserve to be discussed. One explanation may be due to the different forms of POA (Cis or Trans, un- or esterifed) examined in the studies. The POA as a free fatty acid is used or measured in animal and human in vitro studies showed positive effects $[64,66]$. However, when measured in esterified form, the POA may not show its anti-inflammatory effects [52]. Furthermore, studies have shown that lipogenesis is quite different in men and mice models [69]. Therefore, more well-designed studies are required to elucidate on the mechanisms underlying the potentially various associations of POA-in different tissues or in different forms-with inflammation and metabolic abnormalities.

In fact, there are several points to be considered in the present study. Firstly, the observational cross-sectional design did not help identify any causative relationship. Another obvious limitation is the use of fibrinogen and CRP as markers of inflammation. The latter are commonly used because their concentration in plasma is relatively elevated and well above the lowest limit of detection. However, they are considered as non-specific indicators of inflammation and consequently give no information concerning the origin of the inflammatory process. Future research may consider incorporating additional specific markers of inflammation such as IL-1, IL-6 and TNF- $\alpha$. 


\section{CONCLUSION}

BD is a chronic, multi-systemic inflammatory disorder with uncertain pathogenesis. Our objective in this study is to investigate the plasma saturated and monounsaturated FA in BD and its relationship with some inflammatory markers. Data showed that an altered FA profile and enzymes activities would enhance inflammation which would provide important insights into the FA metabolism in BD as well as guide for future biomarker selection. Further researches in larger BD populations in other ethnics with different dietary intake are required to confirm our findings. We would suggest that if our findings are confirmed in future studies, pharmacological interventions targeting SCD-1 activity and level of POA could be considered.

\section{ETHICS APPROVAL AND CONSENT TO PARTICIPATE}

The study was approved by the Committee for the Protection of Persons (CPP).

\section{HUMAN AND ANIMAL RIGHTS}

All procedures performed in this study are in accordance with the ethical standards of the local research committee and with the 1964 Helsinki declaration and its later amendments or comparable ethical standards.

\section{CONSENT FOR PUBLICATION}

All the participant provided informed written consent before being enrolled in this study.

\section{CONFLICT OF INTEREST}

The authors declare no conflict of interest, financial or otherwise.

\section{FUNDING}

This work is funded by the Ministry of Higher Education and Scientific Research of Tunisia.

\section{ACKNOWLEDGEMENTS}

Declared none.

\section{REFERENCES}

[1] Greco A, De Virgilio A, Ralli M, et al. Behçet's disease: New insights into pathophysiology, clinical features and treatment options. Autoimmun Rev 2018; 17(6): 567-75.

[http://dx.doi.org/10.1016/j.autrev.2017.12.006] [PMID: 29631062]

[2] Hatemi G, Yazici Y, Yazici H. Behçet's syndrome. Rheum Dis Clin North Am 2013; 39(2): 245-61. [http://dx.doi.org/10.1016/j.rdc.2013.02.010] [PMID: 23597962]

[3] Oliveira R, Napoleão P, Banha J, et al. Crosstalk between inflammation, iron metabolism and endothelial function in Behçet's disease. Clin Hemorheol Microcirc 2014; 56(2): 175-85. [PMID: 23619201]

[4] Cantarini L, Pucino V, Vitale A, et al. Immunometabolic biomarkers of inflammation in Behçet's disease: Relationship with epidemiological profile, disease activity and therapeutic regimens. Clin Exp Immunol 2016; 184(2): 197-207. [http://dx.doi.org/10.1111/cei.12768] [PMID: 26756979]

[5] Lopalco G, Lucherini OM, Vitale A, et al. Putative role of serum amyloid-A and proinflammatory cytokines as biomarkers for behcet's disease. Medicine (Baltimore) 2015; 94(42): e1858. [http://dx.doi.org/10.1097/MD.0000000000001858] [PMID: 26496336]

[6] Hasan MS, Ryan PL, Bergmeier LA, Fortune F. Circulating NK cells and their subsets in Behçet's disease. Clin Exp Immunol 2017; 188(2): $311-22$.

[http://dx.doi.org/10.1111/cei.12939] [PMID: 28170096]

[7] Fritsche KL. The science of fatty acids and inflammation. Adv Nutr 2015; 6(3): 293S-301S. [http://dx.doi.org/10.3945/an.114.006940] [PMID: 25979502] 
[8] Ghosh A, Gao L, Thakur A, Siu PM, Lai CWK. Role of free fatty acids in endothelial dysfunction. J Biomed Sci 2017; $24(1)$ : 50. [http://dx.doi.org/10.1186/s12929-017-0357-5] [PMID: 28750629]

[9] Marion-Letellier R, Savoye G, Ghosh S. Polyunsaturated fatty acids and inflammation. IUBMB Life 2015; 67(9): 659-67. [http://dx.doi.org/10.1002/iub.1428] [PMID: 26397837]

[10] Siriwardhana N, Kalupahana NS, Moustaid-Moussa N. Health benefits of n-3 polyunsaturated fatty acids: Eicosapentaenoic acid and docosahexaenoic acid. Adv Food Nutr Res 2012; 65: 211-22. [http://dx.doi.org/10.1016/B978-0-12-416003-3.00013-5] [PMID: 22361189]

[11] Finucane OM, Lyons CL, Murphy AM, et al. Monounsaturated fatty acid-enriched high-fat diets impede adipose NLRP3 inflammasomemediated IL-1 $\beta$ secretion and insulin resistance despite obesity. Diabetes 2015; 64(6): 2116-28. [http://dx.doi.org/10.2337/db14-1098] [PMID: 25626736]

[12] Schwingshackl L, Hoffmann G. Monounsaturated fatty acids and risk of cardiovascular disease: Synopsis of the evidence available from systematic reviews and meta-analyses. Nutrients 2012; 4(12): 1989-2007. [http://dx.doi.org/10.3390/nu4121989] [PMID: 23363996]

[13] Gonçalves-de-Albuquerque CF, Silva AR, Burth P, Castro-Faria MV, Castro-Faria-Neto HC. Acute respiratory distress ayndrome: Role of oleic acid-triggered lung injury and inflammation. Mediators Inflamm 2015; 2015: 260465. [http://dx.doi.org/10.1155/2015/260465] [PMID: 26640323]

[14] Shaw B, Lambert S, Wong MH, Ralston JC, Stryjecki C, Mutch DM. Individual saturated and monounsaturated fatty acids trigger distinct transcriptional networks in differentiated 3T3-L1 preadipocytes. J Nutrigenet Nutrigenomics 2013; 6(1): 1-15. [http://dx.doi.org/10.1159/000345913] [PMID: 23392251]

[15] Mu L, Mukamal KJ, Naqvi AZ. Erythrocyte saturated fatty acids and systemic inflammation in adults. Nutrition 2014; 30(11-12): 1404-8. [http://dx.doi.org/10.1016/j.nut.2014.04.020] [PMID: 25280420]

[16] Pararasa C, Bailey CJ, Griffiths HR. Ageing, adipose tissue, fatty acids and inflammation. Biogerontology 2015; 16(2): 235-48. [http://dx.doi.org/10.1007/s10522-014-9536-x] [PMID: 25367746]

[17] Li M, van Esch BCAM, Wagenaar GTM, Garssen J, Folkerts G, Henricks PAJ. Pro- and anti-inflammatory effects of short chain fatty acids on immune and endothelial cells. Eur J Pharmacol 2018; 831: 52-9. [http://dx.doi.org/10.1016/j.ejphar.2018.05.003] [PMID: 29750914]

[18] Kurotani K, Karunapema P, Jayaratne K, et al. Circulating odd-chain saturated fatty acids were associated with arteriosclerosis among patients with diabetes, dyslipidemia, or hypertension in Sri Lanka but not Japan. Nutr Res 2018; 50: 82-93. [http://dx.doi.org/10.1016/j.nutres.2017.12.004] [PMID: 29540275]

[19] Mazidi M, Pennathur S, Afshinnia F. Link of dietary patterns with metabolic syndrome: Analysis of the national health and nutrition examination survey. Nutr Diabetes 2017; 7(3): e255.

[http://dx.doi.org/10.1038/nutd.2017.11] [PMID: 28319105]

[20] Praagman J, Beulens JW, Alssema M, et al. The association between dietary saturated fatty acids and ischemic heart disease depends on the type and source of fatty acid in the European Prospective Investigation into Cancer and Nutrition-Netherlands cohort. Am J Clin Nutr 2016; 103(2): 356-65.

[http://dx.doi.org/10.3945/ajcn.115.122671] [PMID: 26791181]

[21] Santos S, Oliveira A, Lopes C. Systematic review of saturated fatty acids on inflammation and circulating levels of adipokines. Nutr Res 2013; 33(9): 687-95. [http://dx.doi.org/10.1016/j.nutres.2013.07.002] [PMID: 24034567]

[22] Clarke R, Shipley M, Armitage J, Collins R, Harris W. Plasma phospholipid fatty acids and CHD in older men: Whitehall study of London civil servants. Br J Nutr 2009; 102(2): 279-84. [http://dx.doi.org/10.1017/S0007114508143562] [PMID: 19105853]

[23] Ann SJ, Kim KK, Cheon EJ, et al. Palmitate and minimally-modified low-density lipoprotein cooperatively promote inflammatory responses in macrophages. PLoS One 2018; 13(3): e0193649.

[http://dx.doi.org/10.1371/journal.pone.0193649] [PMID: 29518116]

[24] Rodrigues HG, Takeo Sato F, Curi R, Vinolo MAR. Fatty acids as modulators of neutrophil recruitment, function and survival. Eur J Pharmacol 2016; 785: 50-8. [http://dx.doi.org/10.1016/j.ejphar.2015.03.098] [PMID: 25987417]

[25] International Study Group for Behçet's Disease. Criteria for diagnosis of Behçet's disease. Lancet 1990; 335(8697): 1078-80. [PMID: 1970380]

[26] Krause I, Molad Y, Mitrani M, Weinberger A. Pathergy reaction in Behçet's disease: Lack of correlation with mucocutaneous manifestations and systemic disease expression. Clin Exp Rheumatol 2000; 18(1): 71-4. [PMID: 10728447]

[27] Sfikakis PP, Arida A, Panopoulos S, et al. Brief report: Drug-free long-term remission in severe behçet's disease following withdrawal of successful anti-tumor necrosis factor treatment. Arthritis Rheumatol 2017; 69(12): 2380-5.

[http://dx.doi.org/10.1002/art.40235] [PMID: 28834393] 
[28] Desbois AC, Vallet H, Domont F, Comarmond C, Cacoub P, Saadoun D. Management of severe complications in Behçet's disease with TNF inhibitors. Expert Opin Biol Ther 2017; 17(7): 853-9. [http://dx.doi.org/10.1080/14712598.2017.1328496] [PMID: 28503960]

[29] El Ati J. LBG, Haddad S, Eymard-Duvernay S, et al. Food frequency questionnaire for tunisian dietary intakes: Development, reproducibility and validity. Arab J Food Nutr 2004; 5: 10-30.

[30] El Ati JBC, Farhat A, Haddad S, et al. Table de composition des aliments tunisiens. Tunis: INNTA 2007.

[31] Tabata M, Fukunaga C, Ohyabu M, Murachi T. Highly sensitive flow injection analysis of glucose and uric acid in serum using an immobilized enzyme column and chemiluminescence. J Appl Biochem 1984; 6(4): 251-8. [PMID: 6520074]

[32] Friedewald WT, Levy RI, Fredrickson DS. Estimation of the concentration of low-density lipoprotein cholesterol in plasma, without use of the preparative ultracentrifuge. Clin Chem 1972; 18(6): 499-502. [PMID: 4337382]

[33] Sethom MM, Fares S, Feki M, et al. Plasma fatty acids profile and estimated elongase and desaturases activities in Tunisian patients with the metabolic syndrome. Prostaglandins Leukot Essent Fatty Acids 2011; 85(3-4): 137-41. [http://dx.doi.org/10.1016/j.plefa.2011.06.006] [PMID: 21782403]

[34] Kotronen A, Seppänen-Laakso T, Westerbacka J, et al. Comparison of lipid and fatty acid composition of the liver, subcutaneous and intraabdominal adipose tissue, and serum. Obesity (Silver Spring) 2010; 18(5): 937-44. [http://dx.doi.org/10.1038/oby.2009.326] [PMID: 19798063]

[35] Harris WS, Sands SA, Windsor SL, et al. Omega-3 fatty acids in cardiac biopsies from heart transplantation patients: Correlation with erythrocytes and response to supplementation. Circulation 2004; 110(12): 1645-9. [http://dx.doi.org/10.1161/01.CIR.0000142292.10048.B2] [PMID: 15353491]

[36] Kapsimali VD, Kanakis MA, Vaiopoulos GA, Kaklamanis PG. Etiopathogenesis of Behçet's disease with emphasis on the role of immunological aberrations. Clin Rheumatol 2010; 29(11): 1211-6. [http://dx.doi.org/10.1007/s10067-010-1491-6] [PMID: 20495938]

[37] Ohtsu A, Tanaka H, Seno K, Iwata H, Kuwayama T, Shirasuna K. Palmitic acid stimulates interleukin-8 via the TLR4/NF- $\mathrm{B} / \mathrm{ROS}$ pathway and induces mitochondrial dysfunction in bovine oviduct epithelial cells. Am J Reprod Immunol 2017; $77(6): 77$. [PMID: 28185389]

[38] Hwang DH, Kim JA, Lee JY. Mechanisms for the activation of Toll-like receptor 2/4 by saturated fatty acids and inhibition by docosahexaenoic acid. Eur J Pharmacol 2016; 785: 24-35. [http://dx.doi.org/10.1016/j.ejphar.2016.04.024] [PMID: 27085899]

[39] Lancaster GI, Langley KG, Berglund NA, et al. Evidence that TLR4 is not a receptor for saturated fatty acids but mediates lipid-induced inflammation by reprogramming macrophage metabolism 2018. [http://dx.doi.org/10.1016/j.cmet.2018.03.014]

[40] García-Escobar E, Monastero R, García-Serrano S, et al. Dietary fatty acids modulate adipocyte TNFa production via regulation of its DNA promoter methylation levels. J Nutr Biochem 2017; 47: 106-12. [http://dx.doi.org/10.1016/j.jnutbio.2017.05.006] [PMID: 28575756]

[41] Hellmann J, Zhang MJ, Tang Y, Rane M, Bhatnagar A, Spite M. Increased saturated fatty acids in obesity alter resolution of inflammation in part by stimulating prostaglandin production. J Immunol 2013; 191(3): 1383-92. [http://dx.doi.org/10.4049/jimmunol.1203369] [PMID: 23785121]

[42] Cha SH, Hwang Y, Kim KN, Jun HS. Palmitate induces nitric oxide production and inflammatory cytokine expression in zebrafish. Fish Shellfish Immunol 2018; 79: 163-7. [http://dx.doi.org/10.1016/j.fsi.2018.05.025] [PMID: 29772372]

[43] Saadoun D, Wechsler B. Behçet's disease. Orphanet J Rare Dis 2012; 7: 20. [http://dx.doi.org/10.1186/1750-1172-7-20] [PMID: 22497990]

[44] Ito Z, Uchiyama K, Odahara S, et al. Fatty acids as useful serological markers for crohn's disease. Dig Dis 2018; 36(3): 209-17. [http://dx.doi.org/10.1159/000485096] [PMID: 29275413]

[45] Myśliwiec H, Baran A, Harasim-Symbor E, et al. Serum fatty acid profile in psoriasis and its comorbidity. Arch Dermatol Res 2017; 309(5): $371-80$. [http://dx.doi.org/10.1007/s00403-017-1748-x] [PMID: 28585093]

[46] Huang X, Stenvinkel P, Qureshi AR, et al. Clinical determinants and mortality predictability of stearoyl-CoA desaturase-1 activity indices in dialysis patients. J Intern Med 2013; 273(3): 263-72. [http://dx.doi.org/10.1111/j.1365-2796.2012.02573.x] [PMID: 22897446]

[47] Huang X, Sjögren P, Ärnlöv J, et al. Serum fatty acid patterns, insulin sensitivity and the metabolic syndrome in individuals with chronic kidney disease. J Intern Med 2014; 275(1): 71-83. [http://dx.doi.org/10.1111/joim.12130] [PMID: 24011327]

[48] Byberg L, Kilander L, Warensjö Lemming E, Michaëlsson K, Vessby B. Cancer death is related to high palmitoleic acid in serum and to polymorphisms in the SCD-1 gene in healthy Swedish men. Am J Clin Nutr 2014; 99(3): 551-8. 
[http://dx.doi.org/10.3945/ajcn.113.065714] [PMID: 24368438]

[49] Pickens CA, Lane-Elliot A, Comstock SS, Fenton JI. Altered saturated and monounsaturated plasma phospholipid fatty acid profiles in adult males with colon adenomas. Cancer Epidemiol Biomarkers Prev 2016; 25(3): 498-506. [http://dx.doi.org/10.1158/1055-9965.EPI-15-0696] [PMID: 26721667]

[50] The NS, King IB, Couch SC, et al. Plasma trans-palmitoleic acid is associated with cardio-metabolic risk factors in youth with type 1 diabetes. Diabetes Metab 2018; 44(2): 181-4. [http://dx.doi.org/10.1016/j.diabet.2017.02.004] [PMID: 28583347]

[51] Petersson H, Basu S, Cederholm T, Risérus U. Serum fatty acid composition and indices of stearoyl-CoA desaturase activity are associated with systemic inflammation: Longitudinal analyses in middle-aged men. Br J Nutr 2008; 99(6): 1186-9. [http://dx.doi.org/10.1017/S0007114507871674] [PMID: 18062827]

[52] Takkunen MJ, de Mello VD, Schwab US, Ågren JJ, Kuusisto J, Uusitupa MI. Associations of erythrocyte membrane fatty acids with the concentrations of C-reactive protein, interleukin 1 receptor antagonist and adiponectin in 1373 men. Prostaglandins Leukot Essent Fatty Acids 2014; 91(4): 169-74. [http://dx.doi.org/10.1016/j.plefa.2014.07.005] [PMID: 25087591]

[53] Stryjecki C, Roke K, Clarke S, et al. Enzymatic activity and genetic variation in SCD1 modulate the relationship between fatty acids and inflammation. Mol Genet Metab 2012; 105(3): 421-7. [http://dx.doi.org/10.1016/j.ymgme.2011.12.003] [PMID: 22209225]

[54] Button EB, Mitchell AS, Domingos MM, et al. Microglial cell activation increases saturated and decreases monounsaturated fatty acid content, but both lipid species are proinflammatory. Lipids 2014; 49(4): 305-16. [http://dx.doi.org/10.1007/s11745-014-3882-y] [PMID: 24473753]

[55] Cao H, Gerhold K, Mayers JR, Wiest MM, Watkins SM, Hotamisligil GS. Identification of a lipokine, a lipid hormone linking adipose tissue to systemic metabolism. Cell 2008; 134(6): 933-44. [http://dx.doi.org/10.1016/j.cell.2008.07.048] [PMID: 18805087]

[56] Schaeffler A, Gross P, Buettner R, et al. Fatty acid-induced induction of Toll-like receptor-4/nuclear factor-kappaB pathway in adipocytes links nutritional signalling with innate immunity. Immunology 2009; 126(2): 233-45. [http://dx.doi.org/10.1111/j.1365-2567.2008.02892.x] [PMID: 18624726]

[57] Kim F, Pham M, Luttrell I, et al. Toll-like receptor-4 mediates vascular inflammation and insulin resistance in diet-induced obesity. Circ Res 2007; 100(11): 1589-96.

[http://dx.doi.org/10.1161/CIRCRESAHA.106.142851] [PMID: 17478729]

[58] Zhou H, Li Y, Huang G, et al. Interleukin 6 augments mechanical strain-induced C-reactive protein synthesis via the stretch-activated channel-nuclear factor $\kappa$ B signal pathway. Heart 2013; 99(8): 570-6. [http://dx.doi.org/10.1136/heartjnl-2012-303355] [PMID: 23257175]

[59] Kramer F, Torzewski J, Kamenz J, et al. Interleukin-1beta stimulates acute phase response and C-reactive protein synthesis by inducing an NFkappaB- and C/EBPbeta-dependent autocrine interleukin-6 loop. Mol Immunol 2008; 45(9): 2678-89. [http://dx.doi.org/10.1016/j.molimm.2007.12.017] [PMID: 18262272]

[60] Mozaffarian D, Cao H, King IB, et al. Circulating palmitoleic acid and risk of metabolic abnormalities and new-onset diabetes. Am J Clin Nutr 2010; 92(6): 1350-8. [http://dx.doi.org/10.3945/ajcn.110.003970] [PMID: 20943795]

[61] Petersson H, Lind L, Hulthe J, Elmgren A, Cederholm T, Risérus U. Relationships between serum fatty acid composition and multiple markers of inflammation and endothelial function in an elderly population. Atherosclerosis 2009; 203(1): $298-303$. [http://dx.doi.org/10.1016/j.atherosclerosis.2008.06.020] [PMID: 18687433]

[62] ALJohani AM, Syed DN, Ntambi JM. Insights into stearoyl-CoA desaturase-1 regulation of systemic metabolism. Trends Endocrinol Metab 2017; 28(12): 831-42.

[http://dx.doi.org/10.1016/j.tem.2017.10.003] [PMID: 29089222]

[63] Bernstein AM, Roizen MF, Martinez L. Purified palmitoleic acid for the reduction of high-sensitivity C-reactive protein and serum lipids: A double-blinded, randomized, placebo controlled study. J Clin Lipidol 2014; 8(6): 612-7. [http://dx.doi.org/10.1016/j.jacl.2014.08.001] [PMID: 25499944]

[64] Bueno-Hernández N, Sixtos-Alonso MS, Milke García MDP, Yamamoto-Furusho JK. Effect of Cis-palmitoleic acid supplementation on inflammation and expression of HNF4 $\gamma, \mathrm{HNF} 4 \alpha$ and IL6 in patients with ulcerative colitis. Minerva Gastroenterol Dietol 2017; 63(3): 257-63. [PMID: 28185444]

[65] Guo X, Li H, Xu H, et al. Palmitoleate induces hepatic steatosis but suppresses liver inflammatory response in mice. PLoS One 2012; 7(6): e39286.

[http://dx.doi.org/10.1371/journal.pone.0039286] [PMID: 22768070]

[66] Souza CO, Teixeira AA, Biondo LA, Silveira LS, Calder PC, Rosa Neto JC. Palmitoleic acid reduces the inflammation in LPS-stimulated macrophages by inhibition of NFKB, independently of PPARs. Clin Exp Pharmacol Physiol 2017; 44(5): 566-75. [http://dx.doi.org/10.1111/1440-1681.12736] [PMID: 28135761]

[67] Chan KL, Pillon NJ, Sivaloganathan DM, et al. Palmitoleate reverses high fat-induced proinflammatory macrophage polarization via AMPactivated protein kinase (AMPK). J Biol Chem 2015; 290(27): 16979-88. 
[http://dx.doi.org/10.1074/jbc.M115.646992] [PMID: 25987561]

[68] Souza CO, Teixeira AA, Lima EA, et al. Palmitoleic acid (n-7) attenuates the immunometabolic disturbances caused by a high-fat diet independently of PPAR $\alpha$. Mediators Inflamm 2014; 2014: 582197.

[http://dx.doi.org/10.1155/2014/582197] [PMID: 25147439]

[69] Letexier D, Pinteur C, Large V, Fréring V, Beylot M. Comparison of the expression and activity of the lipogenic pathway in human and rat adipose tissue. J Lipid Res 2003; 44(11): 2127-34.

[http://dx.doi.org/10.1194/jlr.M300235-JLR200] [PMID: 12897191]

\section{(C) 2018 Messedi et al.}

This is an open access article distributed under the terms of the Creative Commons Attribution 4.0 International Public License (CC-BY 4.0), a copy of which is available at: (https://creativecommons.org/licenses/by/4.0/legalcode). This license permits unrestricted use, distribution, and reproduction in any medium, provided the original author and source are credited. 